\title{
Dangerous waters: outbreak of eye lesions caused by fresh water sponge spicules
}

${ }^{1}$ Department of Ophthalmology, Otorhinolaryngology and Head and Neck Surgery, School of Medicine of Ribeirão Preto, University of São Paulo, Ribeirao Preto, São Paulo, Brazil

${ }^{2}$ Epidemiological Surveillance Center-Disease Control Coordination - São Paulo State Health Secretariat, São Paulo, Brazil

${ }^{3}$ Invertebrate Zoology Department, Natural Sciences MuseumZoobotanical Foundation of Rio Grande do Sul, Brazil

${ }^{4}$ Butantan Institute, São Paulo, Brazil

${ }^{5}$ Tropical Institute of Medicine, University of São Paulo, São Paulo, Brazil

Correspondence: AAV Cruz, Department of Ophthalmology,

Otorhinolaryngology and Head and Neck Surgery, School of Medicine of Ribeirao Preto, University of São Paulo, Hospital das CIÃnicas-Campus, Campus USP, Ribeirao Preto, São Paulo 14049-900, Brazil Tel: + 5516 36022523; Fax: + 551636022860 . E-mail: aavecruz@fmrp. usp.br

Received: 11 April 2012 Accepted in revised form: 10 December 2012 Published online: 11 January 2013

\begin{abstract}
Purpose To describe an extremely uncommon outbreak of eye lesions in a specific area of the Brazilian Amazonia. Methods Prospective noncomparative case series. Fifty-nine patients who developed eye lesions after swimming in the Araguaia river of Tocantins state in Brazil were examined. A team of ophthalmologists equipped with a slit-lamp, gonioscopic lenses, and indirect ophthalmoscopy performed full eye examination. Analysis of the flora and fauna of the river water was undertaken by a group of experts.

Results and Conclusions Eighty-three eyes were affected. The most common lesions were corneal opacities seen in 34 eyes and conjunctival nodules diagnosed in 12 eyes. Severe visual acuity loss was detected in seven children with unilateral anterior chamber lesions. Spicules of the sponge species Drulia uruguayensis and Drulia ctenosclera were found inside three blind eyes that have been enucleated for diagnostic purposes. All eye lesions could be attributed to an outbreak of foreign bodies from fresh water sponges. Organic enrichment of the water resulting from the absence of sanitation probably was the key factor, which initiated a cycle of ecological imbalance that provoked human disease.
\end{abstract}

Eye (2013) 27, 398-402; doi:10.1038/eye.2012.290; published online 11 January 2013

Keywords: fresh water sponges; foreign body; eye lesions; conjunctival nodules; Amazonia

\section{Introduction}

The basin of the Amazon River covers a large area of the Northern territory of Brazil. The
AA V Cruz', VM Alencar', NH Medina² C Volkmer-Ribeiro ${ }^{3}$, VL Gattás ${ }^{4}$ and E Luna ${ }^{5}$ inhabitants of this part of the country are in constant contact with a complex ecosystem characterized by the ubiquitous presence of water. In 2005, the Public Health Surveillance Secretariat of the Brazilian Ministry of Health was notified that a large number of children living in a town on the Araguaia river right bank in the State of Tocantins were presenting with atypical eye lesions of unknown etiology.

A multidisciplinary team of researchers including ophthalmologists, parasitologists, and biologists was sent to the area and after almost 1 year of intense investigation it was proved that the lesions were provoked by spicules derived from fresh water sponges. ${ }^{1,2}$ We report here the clinical characteristics of this unusual outbreak of eye lesions. We believe that this is the first report of an outbreak of ocular disease because of a foreign body of animal origin.

\section{Materials and methods}

Six ophthalmologists equipped with a slit-lamp, gonioscopic lenses, and indirect ophthalmoscopy examined 59 individuals (118 eyes) during a 4-day trip to the Araguaia river. The sample predominantly consisted of children (40 boys and 19 girls) with a mean $( \pm S D)$ age of $11.6 \pm 6.5$ years. All subjects had been previously selected by the local healthy authorities and signed a consent form.

The criterion for enrollment was a positive history of recent development of eye lesion, such as conjunctival nodules and/or corneal opacity, after swimming in the Araguaia river in the local town (Araguatins). ${ }^{2}$ Examination consisted of the measurement of visual acuity with charts (tumbling Snellen E or letters), external examination with especial attention to eyelids and bulbar conjunctiva, biomicroscopy of the cornea and anterior segment, intraocular 
pressure measurement and, whenever possible, fundus examination by indirect ophthalmoscopy. Two subjects with conjunctival nodules agreed to have their lesions biopsied at the local hospital.

We certify that all applicable institutional and governmental regulations concerning the ethical use of human volunteers were followed during this research.

\section{Results}

Eighty-three eyes were affected, 48 eyes (57.8\%) from 24 subjects with bilateral involvement and 35 from subjects with unilateral disease. All subjects reported the same history: after swimming and diving in the river with open eyes they felt a strong itching sensation in the eyes with redness. Both the itching and redness spontaneously resolved and a few weeks later atypical lesions appeared in one or both eyes. Four categories of lesions were diagnosed: conjunctival nodules, limbar infiltrates, corneal opacities, and anterior chamber inflammatory nodules or masses. As shown in Table 1, in 51 eyes the lesions appeared as isolated findings.

The most common lesions were corneal opacities seen in $34(40.9 \%)$ eyes and conjunctival nodules diagnosed in $12(14.5 \%)$ eyes (Figure 1$)$. The remaining 32 eyes showed different combinations of the main lesion types.

There was no visual loss for $85 \%$ of the eyes that had visual acuities within the 20/20-20/30 range. Moderate losses (20/50-20/70) resulting from corneal clouding were detected in 10 eyes (12.1\%). Only seven children $(6 \%)$ with unilateral anterior chamber lesions presented a severe visual acuity loss (20/200). No subject showed severe bilateral visual impairment.

Anterior chamber lesions induced a strong uveal inflammation and important sequelae. The lesions appeared as white masses in some cases and as anterior synechiae in others (Figure 2). There was a strong association between anterior chamber and corneal lesions. As shown in Table 2, of the 23 eyes with anterior chamber inflammation, only 3 did not show corneal opacities. A highly significant association between corneal and anterior chamber lesions was observed (Fisher test, $P=0 \cdot 0008$ ).

During the biopsies of the conjunctival nodules it became evident that the lesions, in reality, were subconjunctival and extremely adherent to the sclera. Their removal was difficult and induced a round defect in the underlying sclera.

\section{Conclusion}

The fact that a specific population exposed to fresh water was being affected by a constellation of different eye lesions elicited intense interest on the part of the Brazilian Health authorities. For the ophthalmologists involved in the examination of patients, the whole clinical picture was puzzling. No known disease could explain the unexpected combination of conjunctival granulomas, corneal opacities, and intracameral inflammatory masses. The team that examined the children had the strong impression that the constellation of lesions displayed by the patients reflected an agent that was entering the eye from the environment. Some lesions appeared on the inner surface of the outer eye without provoking any uveal reaction. In other eyes, the lesions appeared to protrude into the anterior chamber eliciting an inflammatory process with the formation of anterior sinechiae. In addition, the large number of eyes with external lesions (conjunctiva, limbus, and cornea) and the association between corneal and intracamerular lesions seemed to indicate a disease of external origin.

Initially, aware of a report of a presumed outbreak of trematode-induced granulomas of the conjunctiva in southern India, ${ }^{3}$ a possible helmintic infection was investigated. However, an extensive search for the presence of trematodes in mollusks was negative. During this search it was verified that two exotic species of mollusks, Mellanoides tuberculatus and Corbicula fluminea

Table 1 Distribution of different lesions according to the affected eye, Araguatins, State of Tocantins, Brazil, 2006

\begin{tabular}{|c|c|c|c|c|c|c|c|c|}
\hline \multirow[t]{2}{*}{ Lesions } & \multicolumn{2}{|c|}{$O D$} & \multicolumn{2}{|c|}{ OS } & \multicolumn{2}{|c|}{ OU } & \multicolumn{2}{|c|}{ Total of eyes } \\
\hline & No. & $\%$ & No. & $\%$ & No. & $\%$ & No. & $\%$ \\
\hline Conjunctival nodules & 6 & 17 & 4 & 16 & 1 & 9 & 12 & 14 \\
\hline Limbar infiltrates & - & - & 2 & 8 & - & - & 2 & 2 \\
\hline Corneal opacities & 10 & 28 & 10 & 40 & 7 & 64 & 34 & 41 \\
\hline Intracameral masses & 3 & 8 & - & - & - & & 3 & 4 \\
\hline Multiple lesions & 17 & 47 & 9 & 36 & 3 & 27 & 32 & 39 \\
\hline Total & 36 & 100 & 25 & 100 & 11 & 100 & 83 & 100 \\
\hline
\end{tabular}

Abbreviations: OD, right eye; OS, left eye; OU, both eyes.

Owing to the occurrence of different lesions in each of the eyes, the number of affected subjects with bilateral disease $(n=24)$ is greater than shown in the table. 




Figure 1 Top—left: conjunctival nodule on the temporal aspect of the bulbar conjunctiva. Right-limbar lesion with a depressed center. Note neovascularization and a peripheral corneal ring of opacity. Bottom: left and right corneal lesions.

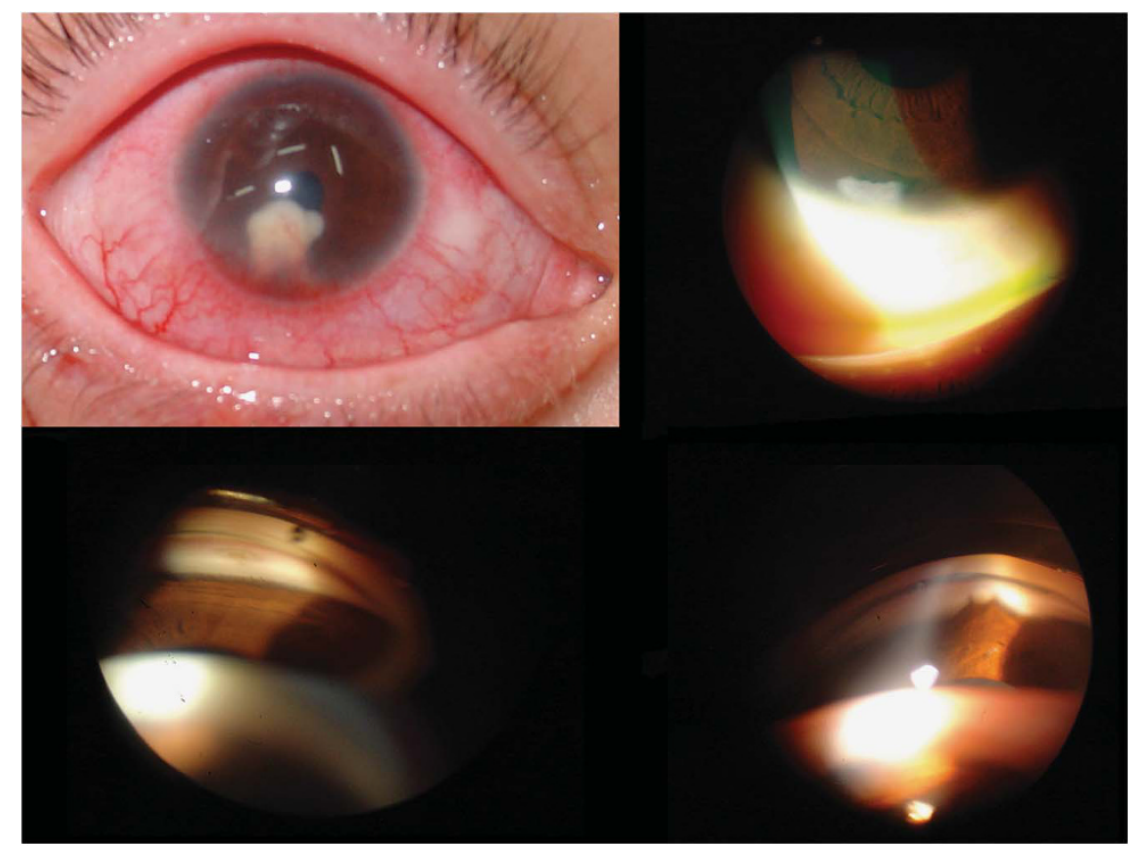

Figure 2 Top-anterior chamber lesions. The lesion on the left was more recent, inducing active inflammation. The lesion on the right was inactive. Bottom-lesions in the anterior chamber angle detected by gonioscopy. Note on the right the anterior synechia induced by the protruding lesion.

were massively present in the riverbank by the town. As in their life cycle, trematodes develop into mollusks, the focus was driven to the examination of these animals.
During the extensive survey of river water that was primarily aimed at the detection of helmintic parasites, another class of organism was identified, that is, the fresh 
Table 2 Association between corneal and anterior chamber lesions, Araguatins, Tocantins, Brazil, 2006

\begin{tabular}{lrrr}
\hline \multirow{2}{*}{ Cornea } & \multicolumn{2}{c}{ Anterior chamber } & Total \\
\cline { 2 - 3 } & + & - & \\
\hline+ & 20 & 46 & 66 \\
- & 3 & 49 & 52 \\
Total & 23 & 95 & 118 \\
\hline
\end{tabular}

Fisher test, $P=0.0008$.

water sponges, which make up a rich and abundant fauna in the Amazonian waters. ${ }^{4}$ Sponges are multicellular animals (Metazoa kingdom) belonging to the phylum Porifera, which is subdivided into three classes, depending on the mineral composition of their internal supporting structure: Hexactinellida,

Demospongiae, and Calcarea. ${ }^{4}$ All fresh water sponges belong to the Demospongiae class where the supporting structures are provided by an apparatus of individual mineral elements, the spicules, composed of noncrystalline silica, that is, opal. ${ }^{4}$ In order to feed, these sessile animals filter the water with a complex network of water-conducting channels and chambers. In this process, they retain a large amount of bacteria and other particulate matter existing in natural waters, thus improving the quality of the water. After the sponges' death, their silicous spicules are released into the water and deposited on the river bottom.

On the riverbank where the affected patients were diving and swimming with open eyes, there was a large amount of spicules of 10 different species of fresh water sponges. The direct link between the fresh water sponge spicules and the outbreak of eye lesions was firmly established when three children with anterior chamber lesions were operated at a teaching Hospital in Minas Gerais state. The analysis of the material obtained from aspiration of the masses disclosed typical gemmoscleres of two species of fresh water sponges, common in the River Araguaia waters, and described in detail in a previous publication. ${ }^{2}$ The finding that fresh water spicules prevalent in the river water were also found within the anterior chamber of some affected eyes provided a simple explanation for the odd spectrum of lesions displayed by the patients. Gemmoscleres are minute spicules that invest the gemmular wall. Owing to their light weight they can stay in suspension in the water. Another interesting feature is their thumbtack shape, which makes them extremely prone to adherence. $^{5}$

There is a large number of articles on different types of intraocular foreign bodies. ${ }^{6,7}$ This literature basically consists of case reports dealing with the technical aspects of diagnosis, extraction, and visual outcomes of the affected eyes. Foreign body migration is a well-known phenomenon. ${ }^{7}$ Depending on the physical properties of the foreign body and the inflammatory reaction induced, the foreign material can penetrate and be found at distant sites from its initial penetration.

The present report is the first to provide a comprehensive description of an outbreak of sponge spicules acting as foreign bodies. It is interesting to note that the deleterious effects of fresh water sponge spicules were well known to the indigenous populations of the Amazon region. ${ }^{2,8}$ For centuries, the native people have avoided waters that 'burn' and itch. These waters were not used for bathing or drinking during a specific period of the year. On the contrary, some native groups reserved these and other species of Amazonian fresh water sponges for pottery because they empirically knew that the high content of hard materials inside these organisms resulted in better ceramic production. $^{5}$

One important question is why only in this particular area of the Araguaia river fresh water sponges became a public health problem. We think that an ecological imbalance was the source of the problem. The local town does not have any sanitation process. Sewage treatment stations were being built but the work was never completed. ${ }^{5}$ During the tourist season, the local population increases substantially and so does the volume of produced sewage that is driven to the river water. Besides, the state of Tocantins is the newest state of Brazil and therefore attracts a large number of migrants. In recent years, the town of Araguatins has presented a dramatic population growth, being one of the largest settlements for landless peasants in the country.

The exotic species of mollusks were invaders who are resistant to anthropically organically enriched waters. Their massive presence was the key factor, which explained the high contents of gemmoscleres in water suspension. As the mollusks were constantly scraping the river, the sponge gemmules failed to fixate and eclode in the rocky substrate of the river. ${ }^{5}$ Before being an agent of disease, the fresh water sponges were in fact being aggressed by the effects of human presence on the river bank.

In terms of medical treatment, we believe that if a person is exposed to water with high contents of gemmoscleres in suspension washing, the eye with abundant sterile water is the first measure to be performed. For those patients who develop intracameral inflammation, we recommend surgery for removal of any debris within the anterior chamber.

We believe that this is the first clinical description of an outbreak of eye disease because of a specific type of foreign body in the ophthalmic literature. This event 
underscores the necessity of caution when tourists interact with unfamiliar ecosystems, especially in disturbed environments.

\section{Summary}

What was known before

- The gemmular wall of fresh water sponges are invested by minute spicules fresh water sponges are found in many rivers of the Amazonia.

What this study adds

- Fresh water sponges can be a source of dangerous foreign body for the eye.

\section{Conflict of interest}

The authors declare no conflict of interest.

\section{References}

1 Mendes MO, Moraes MAP, Renoiner EIR, Dantas MH, Lanzieri TM, Fonseca CF et al. Acute conjunctivitis with episcleritis and anterior uveitis linked to adiaspiromycosis and freshwater sponges, Amazon Region, Brazil, 2005. Emerg Infect Dis 2009; 15(4): 633-639.
2 Volkmer-Ribeiro C, Lenzi HL, Orefice F, Pelajo-Machado M, Alencar LM, Fonseca CF et al. Freshwater sponge spicules: a new agent of ocular pathology. Mem Inst Oswaldo Cruz 2006; 101: 899-903.

3 Rathinam S, Fritsche TR, Srinivasan M, Vijayalakshmi P, Read RW, Gautom R et al. An outbreak of trematode-induced granulomas of the conjunctiva. Ophthalmology 2001; 108: 1223-1229.

4 Müller W, Müller I. Porifera: an enigmatic taxon disclosed by molecular biology. In: Custodio M, Lobo-Hajdue E, G M (eds). Porifera Research. Biodiversity, Innovation and Sustainability. Museu Nacional: Rio de Janeiro, 2007.

5 Volkmer-Ribeiro C, Batista TCA, Melão MCG, FonsecaGessner AA. Antropically dislodged assemblages of sponges (Porifera: Desmospongiae) in the River Araguaia at Araguatins, Tocantins State, Brazil. Acta Limnol Bras 2008; 20: 169-175.

6 Goldsmith MO. Survey of intraocular foreign body literature with special reference to spontaneous migration and extrusion. J Int Coll Surg 1965; 43: 630-640.

7 Tulloh CG. Migration of intra-ocular foreign bodies. $\mathrm{Br} \mathrm{J}$ Ophthalmol 1956; 40: 173-177.

8 Volkmer-Ribeiro C, Batista TCA. Levantamento de cauxi (Porifera, Demospongiae), provável agente etiológico de doença ocular em humanos, Araguatins, rio Araguaia, Estado do Tocantins, Brasil. [Survey for cauxi (Porifera, Desmospongieae), urged by the outbreak of human ocular injuries at Araguatins, Araguaia river, Tocantins State, Brazil]. Rev Brasileira de Zoologia 2007; 24: 133-143. 